\title{
A Framework for Effective User Interface Design for Web-Based Electronic Commerce Applications
}

\author{
Justyna Burns \\ Kent State University
}

\author{
Gregory R Madey \\ University of Notre Dame
}

\begin{abstract}
|rrudnick@bsa3.kent.edu
gmadey@nd.edu

Abstract

Efficient delivery of relevant product information is increasingly becoming the central basis of competition between firms. The interface design represents the central component for successful information delivery to consumers. However, interface design for web-based information systems is probably more an art than a science at this point in time. Much research is needed to understand properties of an effective interface for electronic commerce.

This paper develops a framework identifying the relationship between user factors, the role of the user interface and overall system success for webbased electronic commerce. The paper argues that web-based systems for electronic commerce have some similar properties to decision support systems (DSS) and adapts an established DSS framework to the electronic commerce domain. Based on a limited amount of research studying web browser interface design, the framework identifies areas of research needed and outlines possible relationships between consumer characteristics, interface design attributes and measures of overall system success.
\end{abstract}

Keyword: electronic commerce, user interface design, DSS, system success

\section{Introduction}

There are many existing definitions of electronic commerce, none of which are agreed-upon. But many of them are similar.

$>$ simple definition: Electronic commerce (EC) is the buying and selling of products, services, and information via computer networks.

$>$ more formal definition: EC is a dynamic set of technologies, applications and business processes that link enterprises, consumers and communities through the electronic exchange of goods, services, transactions and information primarily via the Internet, Intranets, and Extranets.

Over the last six years the Internet has challenged businesses to reexamine their methods for delivering products and services. Traditional methods of selling and transacting business in a storefront setting are being replaced by electronic commerce, i.e., the buying and selling and products across globally connected electronic networks. Efficient delivery of rele-

Material published as part of this journal, either on-line or in print, is copyrighted by the publisher of Informing Science. Permission to make digital or paper copy of part or all of these works for personal or classroom use is granted without fee provided that the copies are not made or distributed for profit or commercial advantage AND that copies 1) bear this notice in full and 2) give the full citation on the first page. It is permissible to abstract these works so long as credit is given. To copy in all other cases or to republish or to post on a server or to redistribute to lists requires specific permission and payment of a fee. Contact Editor@inform.nu to request redistribution permission. vant product information is increasingly becoming the central basis of competition between firms. Web-initiated sales were projected to rise from $\$ 1$ billion in 1995 to $\$ 117$ billion in 2000 (Shaw, Gardner and Thomas; 1997). Gartner Group estimated that by $2003 \mathrm{~B} 2 \mathrm{C}$ e-commerce market revenue will surpass $\$ 380$ billion (in 1999 it was $\$ 31.2$ billion, up from $\$ 11.2$ billion in 1998).

Electronic commerce can be classified along several business and technological dimensions. In terms of business models, electronic commerce may be classified as either content delivery (e.g. Yahoo, Excite, Altavista), storefronts (business-toconsumer, or B2C), brokers (consumer-to-consumer, or $\mathrm{C} 2 \mathrm{C}$ ), corporate Intranets and extranets (business-to-business, or B2B), or marketing (informational only).

Content delivery sites are intended to deliver a wide variety of news and information to a worldwide audience. Most information contained in these sites is very dynamic and therefore must constantly be updated; it also has a relatively short period of usefulness. These sites demand responsiveness, reliability, availability, fast performance, and ability to handle denial-of-service attacks and many other factors.

Storefronts are the sites most commonly thought of as electronic commerce sites. The information for these sites is a mix of both static data (product descriptions) and dynamic data (availability and pricing). The data is structured and stored in databases. In order to provide superior customer service these 
User Interface Design for Electronic Commerce

sites demand high security, responsiveness, reliability, availability and fast performance.

Brokers are market-maker sites, i.e. they exist to bring buyers and sellers of products together in a virtual auction setting. EBay is probably the most well known consumer-to-consumer site. The technological demands of these sites are similar to storefronts.

Corporate Intranets and extranets seek to provide information to employees and business partners. Some examples of information stored on Intranets may be corporate newsletters, reports, and policy manuals. Extranets, such as e-purchasing sites, seek to reduce the cost of doing business along the organization's value chain. These sites demand reliability, availability, guaranteed transactional security and security focus on user authentication.

Marketing or informational sites are intended to educate or inform the user about products or services offered by the company. Most organizations, especially smaller ones, are not interested in web sites generating income as much as informing potential customers about their product offerings. The demands for these sites are much simpler; security is not a concern as much as informativeness.

Numerous research issues for electronic commerce are being investigated. Consumer trust in electronic transactions, consumer shopping behavior, transaction security and multienterprise management are just a sampling of the many issues unresearched. For this paper, the focus is less about purchasing issues; rather, it focuses more on informational aspects of electronic commerce, i.e. how electronic commerce can facilitate user satisfaction and overall system success by presenting and delivering information to consumers more effectively.

The future of electronic commerce shows great promise and will change the way consumers behave. Whereas issues such as price, delivery and quality will always be determining factors for purchase, information delivery may become the central criterion in the near future. Electronic commerce is fundamentally different from television or catalog shopping, since it can provide more information in very rich, dynamic, interactive formats. Electronic malls, for example, allow the consumer to search through several product catalogs instantaneously to find the best price for a particular product. Books, compact discs and software are readily through several electronic channels. Today, virtual reality enables items such as clothes and even houses to be "seen" during design stages prior to actual purchase.

Electronic commerce is not without problems. Security concerns, historically the largest impediment to transacting across the web, are gradually being addressed. Another major chal- lenge is information overload-too much irrelevant information for the consumer to absorb in order to make an informed purchasing decision. The human computer intelligent interaction (HCII) research area is concerned with creating more natural and effective ways for humans and computers to interface. Other problems that have been cited in past research are poor customer service, poor product/information quality and technical problems (Fram and Grady, 1997).

The user interface is a critical component of web-based information systems since it effectively harnesses the power of multimedia technology for the user. While an effective interface does not guarantee system success, a poorly designed interface will likely lead to user dissatisfaction and ultimately system failure. The ideal user interface is comprehensible, predictable, and controllable (Shneiderman, 1998). This paper presents a framework that could guide the design of future studies addressing effects of interface design properties on user satisfaction for web-based electronic commerce systems.

\section{Literature Review}

An information system is an arrangement of people, data, process, interfaces, networks and related technologies that interact to support the information needs of an organization, whether it is data processing at a lower-level or decision support for higher-level management (Whitten \& Bentley, 1998). Information system design (ISD) is a complex, organizational process performed by business and systems professionals intended to develop and maintain computer-based information systems (Hoffer, George and Valacich, 1998). The basic objective of an information system is to provide information to a wide group of users who must perform business activities. Frequently, information systems are classified in terms of users. Electronic data processing systems (EPS) meet the needs of employees whose primary business function is to process day-to-day transactions such as adding, deleting and modifying reservations, purchase orders, invoices, etc. Management information systems (MIS) satisfy the needs of supervisors who perform common functions such as addressing exceptions (e.g. overdue orders, late shipments). Decision support systems are designed to support the needs of higher-level managers and analysts whose primary function is to solve problems and make strategic decisions. Web-based information systems (WBIS) are argued to be an extension of decision support systems, since a primary function of a WBIS is to provide information to consumers who make purchasing decisions.

\section{Decision Support Systems}

A decision support system (DSS) is a computer program providing information in a given domain of applications by means of analytical decision models and access to databases 
to support decision makers in making decisions effectively in complex and ill-structured tasks (Klein and Methlie, 1995). Decision support systems allow many types of decision makers at different organizational levels to systematically analyze problems before making a decision. DSS have strategic importance to the organizations and they play essential role in decision making process.

The concept of ill- (or semi-) structured problems is a key concept in DSS. Decisions can be divided into three groups: structured, unstructured and semistructured in terms of decision making. A decision is said to be well structured if the decision maker can identify all elements of the decision process and qualify them for determining the answer (Thierauf, 1982); these types of decisions refer also to repetitive and routine tasks. Ill-structured and unstructured decisions arise when the problem occurs for the first time and there is no clear method for solving it. In these cases, decision makers frequently make decisions based on preferences, opinions, intuition and experience. The nature of the decision support provided by DSS range from passive to active and from individual to group and the goal in designing all decision support systems is to improve "decision quality".

DSS are typically composed of 3 components: a database, a mathematical or graphical models of business processes and a user interface enabling the user to manipulate the data or model to assist in complex decision making. The database is usually extracted from an EDP system or MIS and summarized at different levels of detail. The business model may be a combination of hard historical data as well as judgments or production rules specified by an individual user. Usually the DSS enables a very flexible approach to data analysis since problems are frequently new and unique. The interface not only presents data to the user but also records the decision logic used by the analyst/user.

The DSS research stream originated over 20 years ago and was provided with a solid foundation for ongoing research and development by the works of several authors, such as Keen and Scott Mortan (1978), Bonczek, Hosapple and Whinston (1980), Sprague and Carlson (1982) and Bennett (1983). DSS research borrows from several fields, such as Management Information Systems, Operations Research, Artificial Intelligence and Organizational Theory. Much of the research in the last 2 decades has focused on the database and modeling components of DSS, since the user interface technology was primarily text based. However, in the last 10 years, interface technological improvements have facilitated an increase in the investigation of the user interface component.

While decision support systems have been fairly well researched over the last 20 years, they have not necessarily been successful, especially from the user's perspective. DSS implementation in organizations is difficult since they must satisfy a large group of user who vary in terms of analysis depth, knowledge of business processes and business objectives. DSS implementation is understandably difficult considering the nature of the semi- and ill-structured problems they are required to solve. Alavi and Joachimsthaler (1992) proposed the most frequently cited framework encompassing different perspectives and common themes from a metanalysis in the DSS implementation genre. The core of the framework consists of four sets of user-related factors: cognitive style, personality, demographics, and user-situational variables. These sets are surrounded by task environment factors, organizational environment, and external environment factors.

The emergence of the Internet has offered new approaches to DSS design. The notion of linking many different types of information sources has resulted in different approaches to taking DSS to higher level of sophistication. Hess et al. (2000), for example, develop a framework for incorporating autonomous software agents into DSS design. Software agents are programs utilizing artificial intelligence, which assist the user in the decision-making task and may also act on the user's behalf. The Internet will raise the capabilities of DSS to a higher level, but will also result in greater difficulty in their development.

\section{Web-Based Information Systems}

Web-based information systems (WBIS, or WIS) are an emergent class of information systems that utilize Internet technology and are deployed on the Internet. Web-based information systems (WIS), especially those that incorporate databases as the principal method of data storage, have much in common with traditional information systems. Essentially, web-based information systems follow the 5 stages of planning, analysis, design, implementation and maintenance. However, they also represent an entirely new generation of information system, termed hypermedia applications, since they can take advantage of technological advances such as hypermedia (video, audio, images) and hyperlinking between documents or sites. A WIS is probably better described as a special type of hypermedia application; since the information content of a WIS is dynamic, it differs from other types of hypermedia applications distributed on CDs (e.g. Microsoft's Encarta or Compton's Reference Guides).

Schwabe and Rossi (1998) discuss complexities inherent to web-based applications that are absent from traditional systems. First, navigation poses many problems. The central issue is providing the user with a navigational structure that enables the user to know where they are at a site, where the required information is stored, and the best path to retrieve the information. Traditional information systems could not take 
advantage of hyperlinking; information screens were typically organized in a hierarchical fashion and accessed through menus.

A second major challenge for web-based applications pertains to the complexity of the interface design. The interface is considered to be a critical component of an information system; it serves many functions but is principally a portal for the user to complex information stores. Prior to 1985, virtually all systems were constructed with text-based interfaces. Information was organized in a linear fashion and presented to the user based on a fixed, hierarchical fashion (Ramarapu et. al., 1997). This was done to accommodate the simplicity of the text-based interface and yet still provide the user with a logical, linear presentation of information. For web-based information systems, interface design is argued to be especially critical. A good interface must present information (in the form of objects) to the user in a logical fashion as in traditional systems. In addition, it should accommodate the user's desire to freely roam throughout the information domain space via hyperlinking and yet keep a permanent reference about where he/she is located within the site's domain space.

Traditional ISD methodologies do not adequately support the development of hypermedia software (Schwabe \& Rossi, 1998; Isakowitz et al., 1995). While interface design is usually considered an important component to system success, traditional systems development methodologies do not address the notion of linking; the details on how to incorporate hyperlinks into the interface are scarce. Typically, these methodologies leave interface design as a last step to be completed during system implementation.

To address these concerns, some methodologies have begun to appear in the literature. Isakowitz et al (1995) introduce Relationship Management Methodology (RMM) embodying their view of hypermedia as a vehicle for managing relationships among information objects. Garzotto (1993) discuss Hypermedia Design Model (HDM) as a methodology for analyzing and developing hypermedia applications. Schwabe and Rossi (1998) proposed a more recent methodology, object oriented hypermedia design methodology (OOHDM).

The general objective of a web-based information system (WBIS) for electronic commerce is to achieve customer satisfaction to a point where the consumer will purchase a product or service. A WBIS typically consist of two basic components:

1. A back end, consisting of a product database engine and related application programs designed to process requests from users seeking information about products and services, and
2. A front end, consisting of a user interface that enables the user to make requests and also displays the processed results in one or more web pages.

Although web site architecture and web page design are key elements dictating the success of electronic commerce systems, scientific research in these areas has not developed adequate models or frameworks. Several ideas have been proposed from different perspectives, and these are reviewed briefly here.

Sukpanich and Chen (1999) discuss the benefits of web-based electronic commerce systems from the retailer perspective. Systems are considered to be beneficial if they produce desirable consumer behaviors. Obviously, the most desired consumer behavior is the actual purchase of the product offering. Systems can also produce two indirect behaviors that are beneficial. If the system is educational, it will produce learning about the product, which may lead to purchase. A system may also produce information dissemination, i.e. when consumers tell others about the product, company or web site, which is currently the most common way consumers learn about web sites.

\section{Development Of The Framework}

Web-based information systems are an emergent type of information system that shares much in common with traditional information systems such as decision support systems. This section begins by discussing the similarities and differences between decision support systems and web-based information systems. The remainder of the section is dedicated to the adaptation of a framework outlining factors influencing DSS implementation success toward implementation success for WBIS. The framework is useful since it will guide future research addressing differences in user characteristics and user interface design.

\section{DSS versus WIS}

Web-based electronic commerce systems have much in common with decision support systems. Both types of systems assist users by providing them with information for complex decision-making tasks. Both rely on information retrieval from structured databases by means of some type of analytical decision model varying in complexity. Also, both types of systems must be designed to accommodate a wide variety of users, whether the user is an analyst or manager in an organization or a consumer seeking to purchase a product or service online.

Electronic commerce systems are similar but not identical to decision support systems. The systems differ in at least four respects. First, system usage for B2C electronic commerce 
systems is optional for users as consumers, whereas the usage of DSS by organizational members is more likely to be a mandatory component of an organizational work process. (Although DSS system usage is not necessarily mandatory, their internally-focused system characteristics limit the alternatives for users. Alternatives are typically either cost prohibitive (if available outside the organization) or less efficient (e.g. manual information retrieval systems) and subsequently less attractive to users.) Second, users of DSS are typically involved in the system's design and construction. Many authors have identified user involvement as a major factor governing system success (e.g. Igbaria \& Guimares, 1994; Hartwick \& Barki, 1994). Third, the objectives of each system are different. The measure of success for a DSS is based primarily on the degree to which it is informative; for web-based electronic commerce systems, success is based not only on informativeness but also on the system's tendency to increase consumer's purchasing intent. Fourth, DSS traditionally used text-based interfaces, whereas web-based electronic commerce systems are much more user-friendly due to their graphical, hypertextbased interface.

User choice. Web-based information systems are similar but not identical to decision support systems. Consumers differ from DSS users in that they are not required to use a webbased information system-they can just surf to the next site.

Interface design. The technology is also different. A DSS normally used a text-based interface, whereas a WBIS is much more user-friendly due to its graphical, hypertext-based interface. Unfortunately, the differences are substantial enough to render historical DSS literature as a mere starting point for WBIS research.

The graphical interface utilizes objects on the screen such as icons and a pointing device such as a mouse to assist the user with common tasks. Although it was developed at Xerox in the early 1970s, it did not become popular until Apple developed the Macintosh in 1983. In fact, the graphical user interface (GUI) was a major contributor to Apple's success. By the mid 1990s, most PCs utilized a GUI interface in one form or another.

Hypertext refers to a nonlinear method of presenting information to the user. A hyperlink is an object embedded in one document that links to another potentially useful document for the user. While hypertext has been around since 1960's, it has been met with enormous popularity for the web. Nonlinear, hypertext systems have been shown to improve accuracy in decision making and also user satisfaction when compared to linear systems (Ramarapu et. al., 1997).

Virtually all WBIS utilize a nonlinear, hypertext format for presenting information. The web also has an added feature in that it can present various forms of multimedia (audio, graphics, video) as well as text. The result is a much richer experience for the user. Here again, historical research is limited in its ability to identify factors that will lead to user satisfaction, since the technology is so radically different.

\section{Adapting the Alavi-Joachimsthaler DSS Framework to Web-Based Information Systems}

Alavi and Joachimsthaler (1992) proposed a framework identifying factors influencing DSS implementation success that is relevant to electronic commerce systems. The framework developed by Alavi includes different perspectives and common themes from previous work in the DSS (Alavi, 1992). Their framework defined 4 types of variables influencing system success: user, task, organizational and external environmental. Of particular interest to them were user variables that include personality, cognitive style, user experience, and demographics. Their findings indicated system success was correlated with user involvement in the design process, training and experience, and to a lesser extent, cognitive style and personality. The effects of demographic variables were inconclusive as the number of studies was small.

This paper presents an adaptation of this framework applicable to the domain of B2C electronic commerce systems.

The framework is presented in Figure 1. At the center of the framework is the user interface design argued to be a central contributor to system success. Analogous to a storefront clerk, the user interface facilitates a dialogue between the consumer and product information available within the store. Attributes of an effective interface design include ease of navigation, consistency, attractiveness, informativeness, support for multiple users and purposes, ease of use and efficiency (Kim, 1999; Tennant, 1999).

Systems development methodologies have been proposed that may assist researchers and developers seeking to design nonlinear web-based information systems utilizing a hypertext interface for electronic commerce. User interface design (UID) is a part of the overall system design. The central goal of systems design should be designing UI that will enable people to learn systems quickly, and use them effectively, efficiently, and comfortable. Hager et al (1999) offer some basics of user-friendly web design, such as building prototypes, developing a consistent theme and designing around the users' capabilities. User-centered design is a technique for designing interfaces, such as those used in web-based applications that includes continuous and early focus on the users' tasks and goals. This task is difficult as computer users vary across sev- 


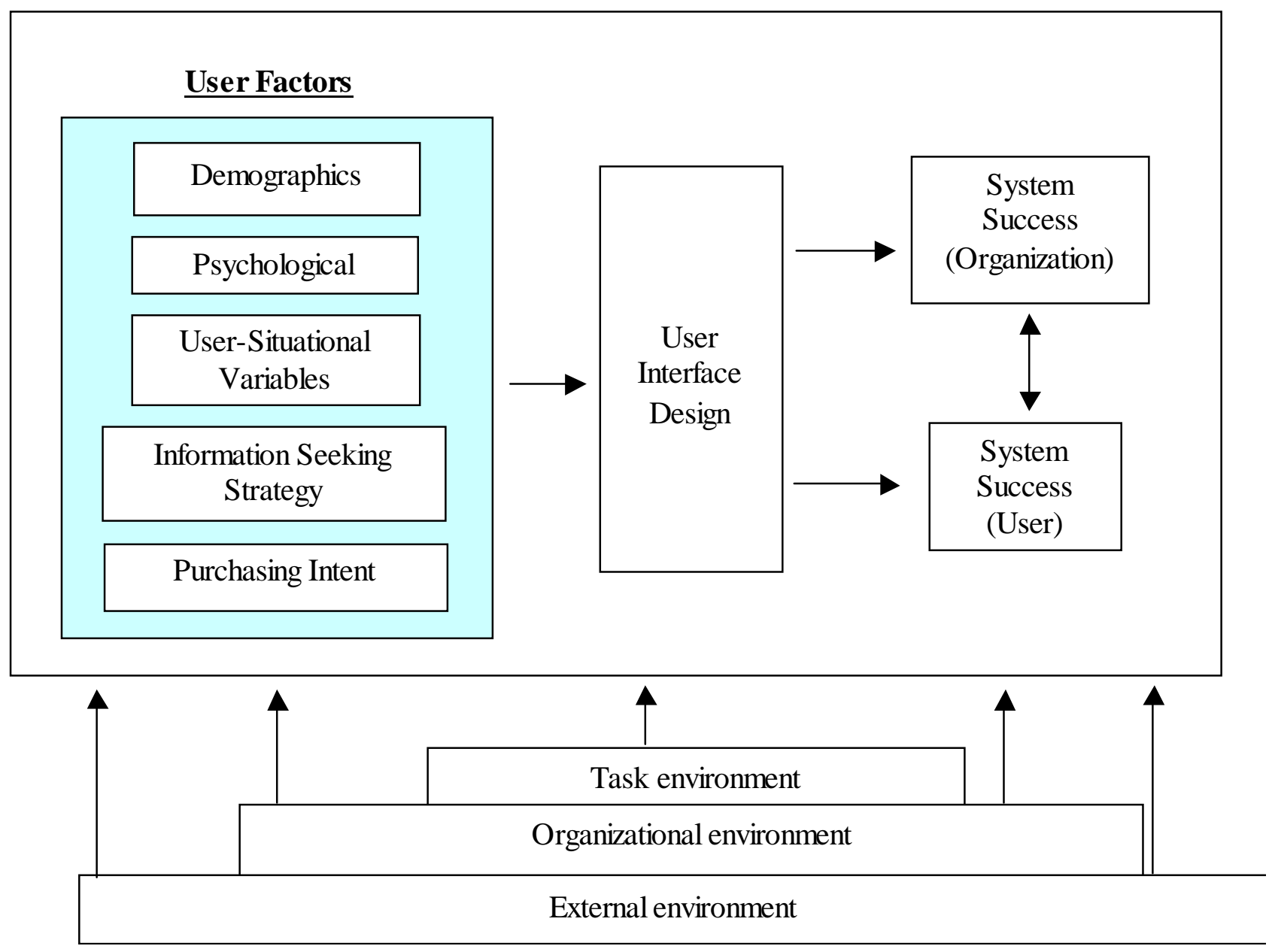

Figure 1: Proposed Framework

eral dimensions, such as personalities, learning styles, cognitive styles, preferences for information display, etc.

The dominant type of interface for electronic commerce applications, the web browser, provides many of these features through its use of multimedia and hyperlinking.

A successful web site design should balance tradeoffs associated with factors such as: 1) page loading, 2) business content, 3) navigation efficiency, 4) security and 5) marketing / consumer focus (Gehrke and Turban, 1999). Page loading refers to the time it takes to load a web page. Business content refers to the quality of presentation and the usefulness of the content to the user. Navigation efficiency refers to the effort required to retrieve information; this can be reflected in overall site design (number of links required to retrieve the correct information) or the effectiveness of a search engine. Marketing / consumer focus refers to how well the site markets its products and services. For example, increasing business content may mean employing forms of multimedia such as video, audio and graphics; however, these forms require substantial bandwidth and processing power at the user end, which may represent excessive delays in page loading.

System benefits from the user perspective are substantially different from the retailer perspective. Ideally, systems should be enjoyable to use and invoke confidence in the consumer regarding their purchasing decisions.

\section{Measures of System Success}

The success or effectiveness of information systems is typically measured in many different ways, such as user satisfaction, system usage, and utility of information systems in decision making (Klenke, 1992)(Park, 2000). User satisfaction is one of the most important and frequently researched constructs in information systems research. For our purposes, the proposed framework identifies two distinct but possibly interrelated measures of system success. From the organization's point of view, system success is defined in terms of the reve- 
nue it generates through purchases and advertising. A consumer's measure of system success is likely very different. Jahng et. al. (1999) cite four measures of system success found in the literature as the impact of the system on user attitude, satisfaction, site recall and recognition, and intent to buy.

User satisfaction is a critical construct and as a surrogate measure it has been used to measure information system success, DSS success, and utility of information systems in decision making (Klenke, 1992).

The extensive list of user variables influencing measures of system success has been summarized by Alavi and Joachimsthaler (1992). Demographic variables include age, gender and education. Psychological factors include cognitive style, personality and attitudes. User situational variables include training, experience, and user involvement in DSS design.

The proposed framework accommodates two other user variables speculated to be important to EC system success: purchasing intent and information retrieval strategy. Belkin et. al. (1993) describes a user's information retrieval strategy for hyperlink systems as browsing (scanning a resource), learning (expanding one's knowledge of one's goal and problem), recognition (identifying relevant items through stimulated association) and meta-information (interaction with resource that describes structure and contents of information objects and resources).

The major task variable for electronic commerce is hypothesized to be the degree of structure associated for a particular purchasing decision. Well-structured problems or decisions are well defined, repetitive tasks. For electronic commerce, these types of decisions are most closely related to "hard" goods, such as compact discs, software and books. Semi- and ill-structured problems or decisions lack a specific method for solution. These types of decisions are probably most applicable to the purchasing of "soft" goods requiring customization by the user. Examples of "soft" goods include clothing, automobiles, personal computers and housing.

The factors dictating whether or not consumers will purchase products are not fully understood. Some products (e.g. books, software, music) are currently being purchased online, whereas others (e.g. clothing) have not been as well received. Liang and Huang (1998) developed a model predicting consumers' likelihood of purchasing products via the web based on the costs of the electronic transaction. Their model suggests that consumer acceptance of the electronic channel is determined by a) the uncertainty of the product they are purchasing, b) potential problems (e.g. security) with the channel itself, and c) asset specificity, i.e. the degree of confidence consumers have in the company, the product features based on the complexity of the product.

Organizational environmental variables are variables unique to a particular organizational setup or design influencing system success. Supply chain configuration, referring to whether the organization is a manufacturer, distributor or "electronic shopping mall", is a potential factor contributing to interface design and overall system success. Brand recognition, reputation, product quality, level of technical support and service after purchasing are other possible factors.

External environmental factors are probably best described as critical success factors dictated by the industry that differentiate products. Critical success factors include importance of quality, delivery, cost and other competitive considerations.

\section{User Interface Design}

Interface design success is more than just attractiveness-the design should vary based on the task to be performed by the user. The technology fit model suggests that system success will be achieved if the technology (interface) fits the task to be performed by the user.

The interface is a major aspect for system success and its role is to define the structure and global logic of application. The basic role of the user interface design is to support the user in acting on an object or with a subject through the artifact (Bødker, 1991). There is an infinite variety of tasks and users, so there's no simple definition of a "good" interface. The designer following the design process must make many decisions, relying on knowledge of users, their cognitive skills and limitations, and their tasks. In addition, the interface design process will only be successful if it is integrated into the software production process as a whole.

The role of the user interface has been proven to be a key factor in user satisfaction. Prior to 1985, systems were constructed with a text-based interface. Information was organized in a linear fashion and presented to the user based on a fixed, hierarchical fashion (Ramarapu et. al., 1997). This was done to accommodate the simplicity of the text-based interface and yet still provide the user with a logical, linear presentation of information.

Given the numerous choices available to EC consumers, it is argued that interface design is the central factor in determining the success of electronic commerce systems. In addition, electronic commerce is fundamentally different from other types of avenues for B2C environments (such as catalog shopping) since it can potentially provide large amounts of relevant information in very rich, dynamic formats. Electronic malls, for example, allow the consumer to search through sev- 


\section{User Interface Design for Electronic Commerce}

eral product catalogs instantaneously to find the best price for a particular product. Books, compact discs and software are readily sold through several electronic channels. Today, virtual reality enables items such as clothes and even houses to be "seen" during design stages prior to actual purchase.

\section{Conclusions}

The framework seeks to identify areas of needed research for electronic commerce. Some studies have begun to surface investigating various relationships highlighted in the framework. For example, while electronic commerce has experienced success in the retailing of hard goods (structured decisions), much less is known about how interfaces should be designed for soft goods requiring customization on the part of the user. The relationship between organizational and consumer measures of system success need to be further defined. As an example, advertising and display of related products may increase revenue for the organization but may distract the user.

At this point in time, interface design for electronic commerce is more an art than a science. An overarching framework is needed to specify the variables and relationships important to interface design and overall system success. This paper presents such a framework identifying classes of user, interface, task, organizational and environmental variables perceived to be important. The framework was adapted from a similar framework for decision support systems.

Although web site architecture and web interface design are key elements dictating the success of electronic commerce systems, scientific research in these areas has not developed adequate models or frameworks to guide research. The proposed framework overarches B2C electronic commerce applications and accommodates several perspectives from different authors, and these were reviewed briefly but more research is needed in order to find out whether or not good design influences customers in their decisions.

\section{References}

Alavi, M. and Joachimsthaler, E. (1992). Revisiting DSS Implementation Research: A Meta-Analysis of the Literature and Suggestions for Researchers, MIS Quarterly, vol. 16 (1), 95-116.

Belkin, J.J., Marchetti, P.G., and Cool, C. (1993). Braque: Design of an Interface to Support User Interaction in Information Retrieval, Information Processing \& Management, vol. 29 (3), 325-344.

Bennett, J.L. (1983). Building decision support systems. Reading, Mass: Addison-Wesley.
Bødker, S (1991). Through The Interface: A Human Activity Approach To User Interface Design. Hillsdale, N.J: Lawrence Erlbaum Associates.

Bonczek, R.H., Holsapple, C.W. and Whinston, A.B. (1980). Future directions for developing decision support systems. Decision Sciences, vol. 11 (1), 616-631.

Downing, C.E. (1999). System Usage Behavior as a Proxy for User Satisfaction: An Empirical Investigation, Information and Management, vol. 35 (4), 203-216.

Fram, E. H. and Grady, D.B. (1997). Internet Shoppers: Is There a Surfer Gender Gap? Direct Marketing, vol. 59 (9), 46-50.

Hager, D., Kibler, C. and Zack, L. (1999). The Basics of User-Friendly Web Design, Association for Quality and Participation, vol. 22 (3), 58-61.

Hartwick, J. and Barki, H. (1994). Explaining the Role of User Participation in Information System Use, Management Science, vol. 40 (4), 440-465.

Hess, T.J., Rees, L.P. and Rakes, T.R. (2000). Using autonomous software agents to create the next generation of decision support systems, Decisions Sciences, vol. 31 (1),1-31.

Hwang, M. I., Thorn, R. G. (1999). The Effect of User Engagement on System Success: A meta-analytical Integration of Research Findings. Information \& Management, vol. 35 (4), 229-236.

Igbaria, M., Guimaraes, T. (1994). Empirically Testing the Outcomes of User Involvement in DSS Development. Omega, vol. 22 (2), 157172.

Jahng, J. Jain, H. and Ramamurthy, K. (1999, September). Product Complexity, Richness of Web-based Electronic Commerce Systems, and System Success: A Proposed Research Framework. Association of Information Systems Conference, Milwaukee, WI.

Keen, P.G.W. and Scott Morton, M.S. (1978). Decision Support Systems: An Organizational Perspective. Reading, Mass: AddisonWesley Pub. Co.

Kim, E. (1999, September). A Model of an Effective Web. Association of Information Systems Conference, Milwaukee, WI.

Klein, M.R., Methlie, L.B. (1995). Knowledge-Based Decision Support Systems with Applications in Business. Chichester, New York: Wiley.

Klenke, K. (1992). Construct Measurement in Management Information Systems: A Review and Critique of User Satisfaction and User Involvement Instruments, INFOR, vol. 30 (4), 325-347.

Liang, T. and Huang, J. (1998). An Empirical Study on Consumer Acceptance of Products in Electronic Markets: A Transaction Cost Model, Decision Support Systems, vol. 24 (1) 29-43.

Park, Soyeon. (2000) Usability, User Preferences, Effectiveness, and User Behaviors When Searching Individual and Integrated FullText 
Databases: Implications for Digital Libraries. Journal Of ASIS, vol.51 (5), p. 456-469

Ramarapu, N.K., Frolick, M.N., Wilkes, R.B. and Wetherbe, J.C. (1997). The Emergence of Hypertext and Problem Solving: An Experimental Investigation of Accessing and Using Information from Linear versus Nonlinear Systems, Decision Sciences, vol. 28 (4), 825-849.

Shaw, M.J., Gardner, D.M. and Thomas, H. (1997). Research Opportunities in Electronic Commerce, Decision Support Systems, vol. 21 (3), 149-156.

Shneiderman, B., Byrd, D. and Croft, W. B. (1998). Sorting Out Searching- A User-Interface Framework for Text Searches, Communications Of The ACM, vol 41 (4), 95-98.

Sprague, R.H. and Carlson, E.D. (1982). Building effective decision support systems. Englewood Cliffs, NJ: Prentice Hall.
Sukpanich, N. and Chen, L. (1999, September). Antecedents of Desirable Consumer Behaviors in Electronic Commerce. Association of Information Systems Conference, Milwaukee, WI.

Tennant, R. (1999). User Interface Design: Some Guiding Principles, Library Journal, October 15.

Thierauf, R. (1982). Decision Support Systems For Effective Planning And Control: A Case Study Approach. Englewood Cliffs, N.J.: Prentice-Hall.

Turban, E and Gehrke, D. (2000). Determinants of e-commerce website. Human Systems Management vol.19 (2), 111-120. 